\title{
Study on the Training Mode of "1-3" for College Student Cadres in the Background of New Media
}

\author{
Xiang Sinuo ${ }^{1,}$, Duan $\mathrm{He}^{1}$, Zhu Yashi ${ }^{1}$, Hao Haiguang ${ }^{1}$ \\ ${ }^{1}$ School of information Science and Engineering/School of Artificial Intelligence, Wuhan University of Science and \\ Technology, Wuhan, Hubei 430081, China \\ *Corresponding author. Email: xiang.sn@foxmail.com
}

\begin{abstract}
With the development of internet technology and the popularity of mobile smart terminals such as mobile phones and tablets, we have announced the "Internet plus" era. In the era of "Internet Plus", the influence of network media has been significantly enhanced, especially the rapid development of new media. The change in the way of information dissemination brought about by the new media has also made the work of college student cadres show new characteristics and face new changes and challenges. This paper studies the training mode of college student cadres by means of new media, and constructs a model of "1 plus 3" for college student cadres based on new media. It provides new ideas for the construction of contemporary student cadre
\end{abstract} team.

Keywords: New media, internet plus, student cadres, comprehensive quality, training model

\section{INTRODUCTION}

According to the "Statistics Report on Internet Development in China" released by the China Internet Network Information Center, by the first half of 2019, the number of internet users in China had reached 854 million, an increase of 25.98 million over the end of last year [1]. The scale of China's mobile internet users has reached 847 million, of which $99.1 \%$ have access to the internet via mobile phones. This shows that China's " Internet Plus " era has arrived.

The influence of new media in the" Internet Plus " era has increased significantly. New media methods such as online self-media, social media, and information media use the internet and mobile phones as media for dissemination, which have a profound impact on the study, work, and life of college students. The space for college student cadre training has been greatly expanded. At the same time, the change in the way of information dissemination brought about by new media has also brought new features to the training of college student cadres, and is facing new changes and challenges.

On the one hand, the college student cadre team is the main grasp of self-management and self-service of college students, and is a powerful assistant for teachers to carry out their work; on the other hand, it is also an advanced collective among college students, which has a certain influence and appeal. Using new media means to strengthen the training and education of student cadres is conducive to improving the level of student management services, forming a "radiation effect" and improving the overall quality of students.

\section{MAIN TEXT}

\subsection{New characteristics of college student cadre training in the new media era}

\subsubsection{The interactive feature of new media enhance the subjectivity of student cadres}

As a new internet ecology, New media pays attention to the communication and interconnection between media and users, users and users, and has significant interactive features. The working methods and thinking modes of student cadres are also being changed to some extent due to the application of new media. Student cadres are no longer blindly accepting tasks assigned by teachers, and the leading role of teachers in the training process is overturned. New media provides a platform for interaction between student cadres, classmates, and teachers. When student cadres work, their subjectivity is strengthened, and the training of student cadres has become a two-way, multi-directional process.

\subsubsection{The multi-temporal nature of new media enables the "full-process" training of student cadres}

In the era of new media, college students obtain information from a variety of channels. The immediacy of new media has led to a sharp increase in the amount of information. The way of student cadre training is no longer 
just uploading and delivering through meetings and talks. Building discussion groups, group building, video conferences, screen recordings, and even sending circle of friends on WeChat have become effective channels for student cadre training. With the help of new media, it is possible to effectively achieve full coverage of student cadres.

\subsubsection{The "hidden" feature of new media is good for grasping the pain points of student cadre training}

New media protects users 'privacy, which makes users' true identity information hidden.[2] Student cadres communicate with a "mask" to a certain extent when working with new media. Emotional changes, problems and dissatisfaction with work arrangements will be vented in the new media. The hidden dialectic of the new media during the training of student cadres is helpful for teachers to find the pain points of the process of student cadre training.

\subsubsection{The sharable feature of new media enhances the affinity of student leaders}

New media has the characteristics of sharing. the process of information exchange and dissemination is equal Student cadres are no longer passively accepting roles, but producers and sharers of information. They can choose to obtain information and education, which further strengthens the people-oriented education concept. Through sharing, the training of student cadres is much more affinity. Effectively alleviate the resistance of student cadres to education.

\section{2. " $1+3$ " student cadre training mode based on new media}

Through the analysis of the characteristics of student cadre training mode in the new media era, it is not difficult to find that the use of new media greatly enriches the ways and means of student cadre training. Combined with the new changes in the ideological behavior of student cadres, this paper constructs a " $1+3$ " student cadre training mode based on new media.

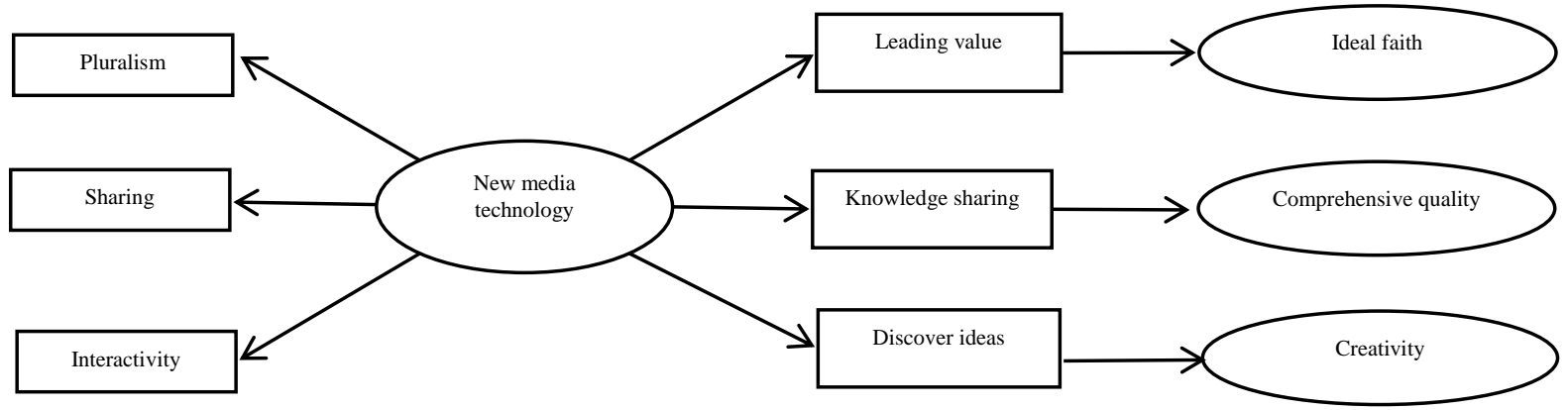

Figure 1 Thinking chart of "1 +3 " training mode

The"1" refers to the new media technology currently used, Which refers to the use of new media technology in the training of student cadres to create a new media platform for student cadre training. Change the traditional training mode and work thinking in the past, and re-understand the changes in the subject, the differences in training methods, and the construction of the system of information transmission and the right to speak in the process of student cadre training. The "3" refers to three important training dimensions in the training of student cadres: ideals and beliefs, comprehensive quality and innovative ability.

\subsubsection{Use new media to realize value guidance and build up the value highland of ideal and belief of student cadres}

The development of new media has transformed the communication mode of college students from interpersonal interaction to socialized communication. The change of social roles has made student cadres exposed to multiple online communities. [3] Accepting massive amounts of information will lead to the chaos of student cadres. Therefore, in the training of student cadres, we must firmly grasp the main line of ideological education and carry out positive publicity and education. Through the "dialogue" methods such as Weibo, WeChat, and online communication and online interaction of the online community, students' cadres are guided to correctly understand school hotspots, online hotspots, and social hotspot issues, cultivate a rational and healthy mentality, and spread positive energy. At the same time, the new media is used to carry out education on the world outlook, outlook on life, and values of student cadres. The content of education is "home-made," "simplified," and "grounded." It is necessary to avoid lengthy preaching and let the student cadres be truly educated with the resilience of dripping stones. 


\subsubsection{Use new media to realize knowledge sharing and improve the comprehensive quality of student cadres}

At present, in the training of student cadres, how to improve the overall quality has always been a bottleneck for educators. The sharing of new media provides a way to solve this problem. In order to improve the efficiency and management capabilities of student cadres, optimize the education content of student cadres, and realize the diversity of education, the characteristics of knowledge sharing of new media can be used to create a knowledge sharing platform for student cadres. [4]

There is no time and space limitation for various activities organized by student organizations, thus promoting student cadres to actively and effectively participate in the activities. In addition to daily ideological education and online interaction, the cultivation of student cadres' values should be extended to practice, and the ideological tasks of student cadres should be strengthened. At the same time, in the context of the current era of data explosion, a positive and green internet atmosphere requires student leaders to take the lead, improve learning, improve practical application capabilities, and implement online and offline in various activities The two-in-one interactive model actively leads the students in organizational ideological work. Under the sharing of new media, student cadres and educators are the main bodies of training and the producers of knowledge, which is conducive to student cadres to accept and learn, and train student cadres to become composite talents.

\subsubsection{Use new media to tap creativity and improve the innovation ability of student cadres}

New media is the center of mass information distribution. Massive information has brought huge data resources, greatly expanded the vision of student cadres, and enriched the imagination space. In the process of cultivating student cadres, it is necessary to guide student cadres to use new media technologies to tap ideas and carry out work creatively. Based on the needs of young people, student cadres are guided to use new media to lead new ideas. [5] Successful online new media themes and special events are mainly aimed at the majority of youth groups. With youth needs as the starting point, they attract attention and participation in the form of new media, thereby inspiring young people's imagination and creativity. College student cadres should make full use of the interactive features of new online media, mobilize initiative and autonomy, use an open and inclusive attitude and respect for equality, reflect the most concerned and most direct practical problems in daily learning and life, lead new ideas, and create new fashion. Avoid degrading and repetitive work, and actively mobilize the enthusiasm of student cadres, so as to improve the quality of work and enhance the innovative ability of student cadres.

\subsection{Issues to be Noted in Using New Media for Student Cadre Training}

New media technology can play an active role in the training of student cadres, but it should also be clearly realized that new media technology is also a "doubleedged sword". Due to the uncertainty, inequality and personalization of information, It is easy to form an island of information. Contemporary college students generally have rebellious psychology. The fanfare of the church has led to student dislike and weakened the effectiveness of student cadre training. Therefore, it is necessary to pay attention to the issue of measurement and degree when using new media to train student cadres.

\subsubsection{Shaky values, unclear value orientation}

People freely speak and communicate on the internet, without being limited by time and space. Thousands of ideas have produced fierce collisions under the big platform of the internet. At the same time, some negative cultural ideas have flooded the internet, and Chinese traditional values are facing severe tests. In the subtle influence of negative thoughts, some incorrect ideas are gradually replacing traditional values, while some incorrect and negative thoughts are regarded by most people as trendy and fashionable. For current college students, value orientation refers to a trend of value pursuit, evaluation and choice. However, there are still many college students who still have unclear value orientations and cannot accurately judge ideas and concepts from the self-networked world. At the same time, some college students who chase individuality are easily exploited by others, or show incompetence, or multiple value standards, which shake their values and cause unclear value orientation.

\subsubsection{Lack of information discrimination}

Many college students lack the ability to identify network information. With the transmission characteristics of new media technology, network information is more confusing in content and form. We are unable to accurately distinguish its true identity. Various student groups and departments publish related information through the network, resulting in too many sources of information. [6] In the media without filtering function, the freedom of online speech has been greatly enhanced. College students are unwilling to express in the real world or be ashamed to convey information and negative psychology wantonly spread in cyberspace. At this time, false and bad content can easily confuse college students, leading to the loss of information recognition ability. 


\subsubsection{Lack of effective communication and Insufficient information dissemination}

If student cadres rely too much on information on media, opportunities for face-to-face communication will diminish. Just passing information through the internet may cause problems such as incomplete information transmission, insufficient strength of important information, and misinterpretation of text meaning. At the same time, network information transmission cannot reach every classmate, and detachment between cadres and student groups occurs, resulting in asymmetric information between student cadres and classmates.

\subsubsection{Out of balance in study and work}

Student cadres spend most of their time on online and offline affairs. Individuals do not have enough time to study. Even a small number of student cadres sacrifice their study breaks to complete related student work. Their first and second classrooms are biased in their energies, they are unable to coordinate development, and their work is unbalanced. In the case of unsatisfactory learning, it is difficult to concentrate on work, leading to a vicious circle.

\section{CONCLUSION}

College student cadres are the organizers, coordinators and executors of student work and an important part of the student work team. The development of new media to the cultivation of the college student cadres and management provides a new convenient, rapid and efficient platform. Based on the current new media technology, the "1+3" mode of student cadres in colleges and universities reexamines the change of subjects, the difference of training means, and the construction of information transmission and discourse power system in the training process of student cadres, and actively innovates and develops the training path of student cadres in colleges and universities. It aims to cultivate and improve the ideals, beliefs, comprehensive qualities and innovative abilities of student cadres, and give full play to the "leading role, assistant role, bridge role, cohesion role, service role" of student cadres. It improves the level of student management services, helps students grow into talents, and serves the great cause of socialist higher education. It is believed that with the continuous development of new media, student cadre team will play a more incomparable role in college student work.

\section{REFERENCES}

[1] China Internet Network Information Center, (2019) The 44th China Statustical Report on Internet Development http://www.cac.gov.cn/201908/30/c_1124938750.htm
[2] Zheng Xiaojun, Legal Considerations of New Media in Colleges and Universities Carrying out Law Education. Zhejiang Education Science, (2018)3:20-22.

[3] Feng feng, On the Innovation of Working Methods of College Student Cadres in the New Media Era. The Theory and Practice of Innovation and Entrepreneurship, (2019)6:146-147+149.

[4] Wang Tingcui, Practice and Exploration of College Student Cadre Team Construction under the Background of New Media, Ability and Wisdom, (2019)22:53-53

[5] Kou Yusheng, Ying Zhongkai, Research on Network of Legal Education in Colleges and Universities. Southeast Academic, (2011)4:243-248.

[6] Wang Yan, On the Causes of the Lack of Network Information Identification Ability of College Students in the New Media Era. Research on Transmission Competence, (2018)17:196-197 